last twenty-five years. This book "Conditioned Reflexes" will be to many a revelation of a new country. After the loose talk and looser thinking which characterizes much of the socalled "psychology" of the present day, it is as refreshing as getting out into the fresh air after being in the fuggy miasma of a tropical jungle. Here we have no cloud-soaring superstructure of argument based on unverified and often incredible assumptions, but simple plain statements of measured actions and reactions, and deductions therefrom. If psychology is ever to become a science Pavlov has shown how it may come about. It is not easy reading; the country is new and the paths are not well-trodden, but Pavlov's book takes its place with those of Sherrington and Magnus in forming what we have called "a great neurological triad." The knowledge contained in these three great works will give the student of the future a sure foundation on which to build up a true science of psychology.

Though mainly neurological in their interest there is much of value to the ophthalmologist, especially in the work of Magnus on ocular reflexes controlled by the labyrinth and the conditioned reflexes of Pavlov resulting from visual stimuli.

\title{
Monograph Supplements and Books
}

This journal, as our readers are aware, has on three occasions distributed to its subscribers valuable monographs which it would have been impossible, on account of their size, to publish in an ordinary issue. These three : "Parenchymatous Keratitis," by Holmes Spicer ; "Retinal Venous Thrombosis," by R. Foster Moore; "Biochemistry of the Aqueous humour," by W. S. DukeElder, have, we know, been much appreciated.

Early in the New Year the journal embarks on a new venture, the publication of "The Development of the Human Eye," by Miss Ida Mann. The printing and publishing will be in the hands of the Cambridge University Press. It is not our place to praise our own children before they see the light, but those of us who have had the privilege of seeing the manuscript are convinced of its value. Miss Mann has already shown her capacity for the work in several papers and exhibits. Further, there is no book in the English language in which the known facts of ocular development are specially dealt with. Bach and Seefelder (in German) appeared before the war and Versari's valuable contributions to the subject (in Italian) have never been collected into one volume from the various journals in which they appeared. The value of such a book is not confined to the theoretical questions involved, important as these should be to all ophthalmologists. The work has a very practical value in the 
diagnosis of congenital defects likely to be met with in practice, always a subject of considerable difficulty.

All of us who have done any research work of a nature not of use in a student's text-book have been met with the difficulty of securing publication, particularly in the case where many illustrations are essential, and when the public addressed can only be a very limited one. It will be remembered that when the company which owns the British Journal of Ophthalmology was originally founded the main purpose was not the earning of dividends but the furthering of the best interests of British ophthalmology. There can be no question of the value of the publication of important works such as the one we are now proposing to issue. We trust that the support extended to this venture may be sufficient to encourage further efforts at a later date.

Reference to our advertisement columns will show that a considerable reduction in price is offered to those who subscribe before publication.

\section{THE INTERNATIONAL OPHTHALMOLOGICAL CONGRESS, I929}

THE Committee of Dutch Ophthalmological Surgeons who are organizing the Congress to be held at Amsterdam in September, 1929 , have already made considerable progress in their arrangements and ophthalmologists may all expect to receive in the near future a preliminary notice and invitation. At the request of the National Committee, two of the non-Dutch officials of the International Council recently visited Leiden and spent two strenuous days in consultation with the President, Professor van der Hoeve, and the two secretaries, Dr. Marx, secretary of the International Council and Professor Zeeman, secretary of the National Committee. At these meetings the following provisional arrangements were made :

The Congress will open at Amsterdam on Thursday, September 5,1929 , in the afternoon, with a General Meeting and reception of delegates. The offices of the Congress will be open from 9 o'clock that morning for members to inscribe their names and receive their cards of invitation and dinner tickets, etc. In the evening there will be a reception by the Burgomaster of Amsterdam. The scientific meetings will take place twice daily on Friday, Saturday, Monday, and Tuesday, at Amsterdam, and on Thursday and Friday at Scheveningen. On Saturday evening the seventh, at Amsterdam, there will be a special concert, and Monday evening 